\title{
Süt sağım makinası vakum pompalarında farklı vakum basınçlarının bazı parametre değerlerine etkilerinin belirlenmesi
}

\author{
Halil ÜNAL ${ }^{1}$, Șilan URAL ${ }^{2}$, Hasan BAYAT ${ }^{2}$
}

1Uludağ Üniversitesi, Ziraat Fakültesi, Biyosistem Mühendisliği Bölümü, Bursa

2Uludağ Üniversitesi, Fen Bilimleri Enstitüsü, Biyosistem Mühendisliği Anabilim Dalı, Bursa

Alınış tarihi: 18 Haziran 2018, Kabul tarihi: 13 Şubat 2019

Sorumlu yazar: Halil ÜNAL, e-posta: hunal@uludag.edu.tr

\section{$\ddot{0} \mathbf{z}$}

$\mathrm{Bu}$ çalışmada, süt sağım makinası vakum pompalarında farklı vakum basınçlarının hava debisi, güç gereksinimi, özgül enerji tüketimi, birim güç başına pompa hava debisi ve gürültü seviyesine etkileri incelenmiștir. Araştırmada motor ve pompa devirleri, maksimum pompa basınçları ve yağ tüketimleri de belirlenmiştir. Çalıșmada farklı kapasitelerde 4 adet vakum pompası kullanılmıștır. Vakum pompalarının $50 \mathrm{kPa}$ basınçtaki hava kapasiteleri firma kataloğunda sırasıyla 600, 1200, 1500 ve $2000 \mathrm{~L} /$ dak'dır. Bu pompalar sırasıyla VP-1, VP-2, VP-3 ve VP-4 olarak isimlendirilmiştir. Denemelerde pompa basınçları olarak 42, 44, 46, 48 ve $50 \mathrm{kPa}$ seçilmiștir. Araștırma sonuçlarına göre, motor devri, pompa devirleri ve yağ tüketim değerleri farklı vakum basınçlarından etkilenmemiş, tüm basınçlarda aynı devir sayıları ve yağ tüketimlerini vermiştir. Dört farklı pompanın kendi aralarındaki motor devir sayılarında ve maksimum pompa basınçlarında istatistiki olarak bir fark olmamış ( $\mathrm{P}>0.05)$, ancak pompa devir sayılarında ve yağ tüketimlerinde istatistiki olarak fark görülmüştür $(\mathrm{P}<0.05)$. Vakum pompaları içerisinde $50 \mathrm{kPa}$ basınçta firmanın belirttiği kapasite büyüklüğünü VP-2 (1203 L/dak) ve VP-3 (1570 L/dak) tipi pompalar sağlamıştır. VP-1 pompası kapasitesinin \%3, VP-4 pompa ise \%13 düzeyinde daha az hava kapasitesi vermiştir. VP-4 pompası hariç diğer pompalar tüm vakumlarda anma motor güçlerinin altında güç tüketmişlerdir. VP-4 tipi pompanın anma motor gücü, $42 \mathrm{kPa}$ basınçta $\% 16$, $50 \mathrm{kPa}$ basınçta ise \%23 daha fazla oranda güç tüketmiștir. VP-3 tipi vakum pompası tüm basınçlarda en yüksek birim güç başına hava debisi (42 kPa'da 556.6 L/dak kW, $50 \mathrm{kPa}$ da $401.8 \mathrm{~L} /$ dak kW) vermiştir. Özgül enerji tüketimi en düşük pompa VP-3, en yüksek ise VP-1 tipi pompada gerçekleşmiştir. 42-50 kPa vakum aralıklarında en düşük gürültü seviyesi VP-2 tipi pompada bulunmuştur.

Anahtar kelimeler: Süt sağım makinası, vakum pompası, hava debisi, birim güç başına pompa hava debisi, güç ve özgül enerji tüketimi, gürültü seviyesi

\section{Determination of the effects of different vacuum pressures on some parameter values in milking machine vacuum pumps}

\begin{abstract}
In this study, the effects of different working vacuums on the air flow rate, power consumption, specific energy consumption, pump efficiency and noise level in vacuum pumps of milking machine were investigated. The engine and pump cycles, maximum pump vacuum and oil consumption were also determined in the study. In the study, 4 vacuum pumps with different capacity sizes were used. The air capacities of the vacuum pumps at the pressure of $50 \mathrm{kPa}$ are $600,1200,1500$ and $2000 \mathrm{~L} / \mathrm{min}$ respectively in firm basis. These pumps are named VP-1, VP-2, VP-3 and VP-4, respectively. In the experiments, pump vacuums of $42,44,46,48$ sand $50 \mathrm{kPa}$ were selected. According to the results of the research, it has been found that the engine and pump cycles and oil consumption values are not affected by different working vacuums, all vacuums have the
\end{abstract}


same cycle numbers and oil consumption. There was no statistically significant difference $(P>0.05)$ between engine speeds and maximum pump vacuum among the four different pumps, but there was statistically significant difference between pump speeds and oil consumption $(\mathrm{P}<0.05)$. Within the vacuum pumps, the capacities of VP-2 $(1203 \mathrm{~L} / \mathrm{min})$ and VP-3 $(1570 \mathrm{~L} / \mathrm{min})$ specified by the firm at 50 $\mathrm{kPa}$ vacuum are maintained. $3 \%$ of the capacity of the VP-1 pump, and $13 \%$ of the capacity of the VP-4 pump. Except for the VP-4 pump, all pumps consumed power below rated motor power at all operating vacuums. The rated motor power of the VP-4 type pump consumed $16 \%$ at $42 \mathrm{kPa}$ and $23 \%$ more at $50 \mathrm{kPa}$. The VP-3 type vacuum pump delivered the highest yield $(556.6 \mathrm{~L} / \mathrm{min} \mathrm{kW}$ at 42 $\mathrm{kPa}$ and $401.8 \mathrm{~L} / \mathrm{min} \mathrm{kW}$ at $50 \mathrm{kPa}$ ) at all operating vacuums. The lowest specific energy consumption was achieved with the pump VP-3 and the highest with the VP-1 type pump. The lowest noise level in the 42-50 kPa vacuum ranges was found on the VP-2 type pump.

Key words: Milking machine, vacuum pump, air flow, pump efficiency, power and specific energy consumption, noise level

\section{Giriș}

Ülkemiz süt sığırcıllğındaki gelişmeler, beraberinde makinalı sağımı da önemli kılmıştır. Süt verimi yüksek hayvanların çoğalması ve işletme sayısındaki artış, ülkemizde seyyar sağım makinalarının yerini, birim zamanda daha fazla hayvanın sağılmasına olanak sağlayan merkezi sağım tesislerinin kullanımını önemli ölçüde artırmıştır. 1990'lı yıllara kadar büyük bir kısmı dış ülkelerden getirilen seyyar süt sağım makinalarının tamamına yakını, günümüzde yerli üretilmektedir. Geçmişte orta ve büyük ölçekli süt sığırcılığı işletmelerinin hemen hemen tümünde ithal markalı sabit süt sağım tesisleri mevcut iken, günümüzde yerli sanayinin önemli atılımlarıyla dengelenmiş durumdadır. Merkezi sağım odalı süt borulu tip tesisler ile gügümlü sağım makinalarındaki aynı anda sağılan hayvan sayısının artması yönündeki yetiștirici talepleri, imalatçı firmaların sağım ünitesi sayısını artırma yoluna sevk etmiştir. Fakat, belki de sorun ya da sorunlar bundan sonra başlamaktadır. Çünkü, tesislerdeki sağım ünitesi sayısının artırılması, standartlarda belirtilen basınç ve hava debilerinin istenilen koşullarda elde edilmesi zorluğunu beraberinde getirmektedir.
Gürültü ve titreşim, sağımcı ve hayvan için rahatsız edici olduğu kadar, sağım sisteminin vakum stabilitesi üzerinde olumsuz bir etkiye sahip olabilir (Nosal ve Bilgery, 2004; TS ISO 5707, 2014). İnekler, tam verim potansiyellerine sadece kendilerini rahat hissettikleri ortamlarda ulaşılabilmektedir. Sağım odası bu ortamı şekillendirmede önemli bir rol oynamaktadır. Pompa gürültü düzeyinin minimize edilmesi için vakum pompası grubunun olabildiğince izole edilmiş bir oda veya ortam içine konulması gereklidir. Sağım odası ortamındaki gürültü seviyesi ortalama $75 \mathrm{~dB}$-A düzeylerinde olması arzu edilir. Aksi taktirde, inekler sağım odasına girmek istemez, inekler memelerinin tamamen boşaltılmasına izin vermez, sağım sırasında ve sonrasında kendini iyi hissetmez ve strese girer (Nosal ve Bilgery, 2004).

Makinayla süt sağımın başarısı, hayvan ve kullanan insan faktöründen çok sağım makinasının yapısal ve işlevsel özelliklerinin sağımın isteklerine cevap verebilmesine bağlıdır. Makinaya imalat veya kurulum (montaj) sırasında kazandırılan tüm yapısal özelliklerin, çiftlik şartlarındaki işletme sırasında da değişmeden kalması gerekir. Burada en önemli görev vakum pompasına düşmektedir (Mein ve ark., 1994; Mein ve ark., 1995; Bray, 1996; Anonim, 2012). Vakum pompası, bir süt sağım makinasının kalbi konumundadır ve sağım makinası sisteminden dışarıya sürekli olarak hava boşaltmak temel görevidir. Böylece sistem içinde sağım için gerekli olan vakum meydana gelir. TS ISO 5707 (2014) ve TS ISO 6690 (2014) standartları, sağımdaki işletme vakum değerinin $42-50 \mathrm{kPa}$ arasında olduğu ve çalışma sırasında vakumda izin verilebilecek en yüksek sapmanın $\pm 2 \mathrm{kPa}$ olması gerektiğini göstermektedir. Diğer taraftan, sağımda bir vakum pompasının kapasitesi, esas olarak sağımın gerçekleştiği sağım ünitesi sayısı ve yüksekliğe (rakıma) bağlıdır. Vakum pompası kapasitesini etkileyen diğer faktörler; sistemdeki temizleme ünitesi, otomatik başlık çıkarıcı, pulsatör tipi ve sistemdeki hava kaçaklarıdır (Chilvers ve Love, 1986; Ünal, 2013; TS ISO 5707, 2014). Yapılan ulusal ve uluslararası araștırmalarda süt sağım makinalarında kullanılan farklı kapasitelerdeki vakum pompalarının performans değerlendirmeleri üzerine kapsamlı bir bilimsel araştırmaya rastlanılmamıştır.

$\mathrm{Bu}$ araştırmanın amacı, yarı sabit kovalı süt sağım makinaları ve süt borulu sağım makinalarında kullanılan dört farklı tip vakum pompasının (VP-1, VP-2, VP-3 ve VP-4) yapısal ve işlevsel özellikleri, 
sağım tekniği ve isteklerine uygunluk derecelerini belirlemektir. Ele alınan vakum pompalarının farklı ișletme vakum basınçlarının (42-50 $\mathrm{kPa}$ arasında 2 kPa aralıklarla,) hava kapasitesi, güç ve özgül enerji gereksinimi, birim güç başına pompa hava debisi ve gürültü seviyesi etkilerini saptamak için temel ölçüm ve hesaplamalar yapılarak karşılaştırılmıştır. Ayrıca, vakum pompalarının 42-50 kPa arasındaki belirtilen parametreleri belirlemek için regresyon ilişkileri incelenmiș ve deniz seviyesinde pompaların hava kapasitelerine göre sağım yapabileceği ünite sayıları belirlenmiştir.

\section{Materyal ve Yöntem}

$\mathrm{Bu}$ çalışmada, yarı sabit kovalı süt sağım makinaları ve süt borulu sağım makinalarında kullanılanfarklı hava kapasitelerine sahip yağlı, döner kanatlı ve motora kayış-kasnak bağlantılı dört adet vakum pompası kullanılmıştır. Vakum pompaları yerli üretici tek bir firmadan temin edilmiştir. Vakum pompalarının $50 \mathrm{kPa}$ basınçtaki hava kapasiteleri firma kataloğunda sırasıyla 600, 1200, 1500 ve 2000 L/dak belirtilmiștir. Pompa, yatay bir silindir gövde ve eksantrik olarak bağlanmış bir rotordan oluşmuştur. Rotor, silindir gövde ile üst tarafa temas halindedir. Rotor ve gövde arasındaki boşluk hilal şeklindedir. Pompa giriş ağzı vakum boru hattının uzantısı, çıkış ağzı ise eksoz borusunun uzantısıdır. Rotor, 4 adet yuvaya sahiptir. Bu yuvalar, rotorun dönüşüne radyal olarak serbestçe kayarak girip çıkan kanatların yatağıdır. Kanatlarla gövde arasında merkezkaç kuvvetiyle oluşan temas sonucu sürtünmeleri önlemek için, kanatlar fiber malzemeden yapılmıştır. Kanatlar, sürtünme kayıplarını azaltmak için gövde yüzeyine teğet olarak kaymakta ve kanatlar arasında kalan hava, kanatların dönmesiyle girişten çıkışa doğru götürülmektedir. Vakum pompalarının vakum üretme grubu üniteyi taşıyan bir şasi, trifaze elektrik motoru, motordan kayış-kasnak ile hareket alan yağlı tip vakum pompası, yağlama kabı, vakum tankı (yedek hava deposu) ve eksoz ünitesinden oluşmaktadır (Şekil 1). Pompaların önemli teknik özellikleri Çizelge 1'de verilmiştir.

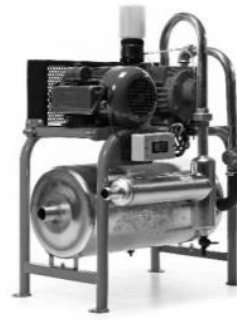

VP-1

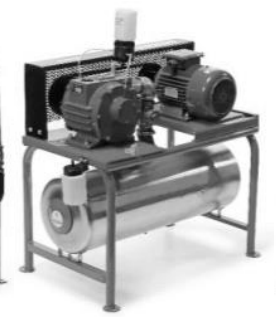

VP-2

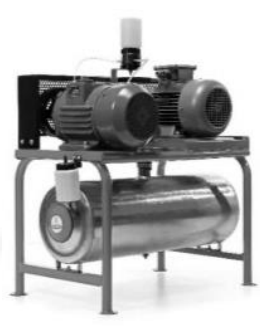

VP-3, VP-4
Şekil 1. Araştırmada kullanılan farklı tip vakum pompa tipleri

Vakum pompası deneyleri, imalatçı firmanın laboratuvarında gerçekleștirilmiștir. Laboratuvar deneylerinde, çalışma ortamı sıcaklığı $\left({ }^{\circ} \mathrm{C}\right)$, bağıl nem $(\%)$, gerçek atmosfer basıncı $(\mathrm{kPa})$ ve rakım $(\mathrm{m})$ gibi veriler belirlenmiștir. Sıcaklık ve bağıl nem sırasıyla $0.1^{\circ} \mathrm{C}$ ve $\% 1$ hassasiyete sahip bir termo-higrometre kullanılarak ölçülmüştür.

Çizelge 1. Vakum pompaları ve elektrik motorların bazı teknik özellikleri

\begin{tabular}{|c|c|c|c|c|}
\hline \multirow{2}{*}{ Parametre } & \multicolumn{4}{|c|}{ Vakum pompası tipi } \\
\hline & VP-1 & VP-2 & VP-3 & VP-4 \\
\hline \multicolumn{5}{|l|}{ Vakum Pompasl } \\
\hline Kanat ölçüleri (K x G x U)*, (mm) & $6 \times 70 \times 109.8$ & $6 \times 70 \times 159.8$ & $6 \times 70 \times 224.8$ & $6 \times 70 \times 224.8$ \\
\hline Stator çapı x uzunluğu, (mm) & $\varnothing 137 \times 110$ & $\varnothing 170 \times 160$ & $\varnothing 170 \times 225$ & $\varnothing 170 \times 225$ \\
\hline Rotor çapı x uzunluğu, (mm) & $\varnothing 110 \times 109.8$ & $\varnothing 139 \times 159.8$ & $\varnothing 139 \times 224.8$ & $\varnothing 139 \times 224.8$ \\
\hline Giriș ve çıkıș çapları, (inç) & $1^{\prime \prime}-1 "$ & $1 \frac{1 / 2 "}{2}-1 \frac{1 / 2 "}{}$ & $11 / 2 "-11 / 2 "$ & $1 \frac{1 / 2 "}{\prime \prime} 1 \frac{1}{2 \prime \prime}$ \\
\hline Katalog hava kapasitesi, (50 kPa'da) (L/dak) & 600 & 1200 & 1500 & 2000 \\
\hline \multicolumn{5}{|l|}{ Elektrik Motoru } \\
\hline Tipi & VM $100-4$ & VM $112-4$ & VM $112-4$ & VM 112-4 \\
\hline Güç, Devir, (kW - dev/dak) & $2.2-1400$ & $3-1405$ & $4-1425$ & $4-1425$ \\
\hline Çalıșma gerilimi, akım, frekans, (V - A - Hz) & $380-5.3-50$ & $380-6.9-50$ & $380-8.6-50$ & $380-8.6-50$ \\
\hline \multicolumn{5}{|l|}{ Kayıș-Kasnak Düzeni } \\
\hline Motor ve pompa kasnakları çapı, (mm) & $\varnothing 100-\varnothing 125$ & $\varnothing 140-\varnothing 180$ & $\varnothing 130-\varnothing 180$ & $\varnothing 160-\varnothing 180$ \\
\hline V kayıș sayısı x genișliği x uzunluğu, (mm) & $1 \times 13 \times 1000$ & $2 \times 17 \times 1375$ & $2 \times 17 \times 1300$ & $2 \times 17 \times 1350$ \\
\hline
\end{tabular}

Deniz seviyesinden yükseklik ve atmosfer basıncı el tipi dijital bir cihaz (OREGON, RA123, 1-10.000 m arası yükseklik) kullanılarak ölçülmüştür. Atmosferik basınç hPa'da ölçülmüş ve kPa'ya (1 hPa
$=0.1 \mathrm{kPa}$ ) dönüştürülmüştür. Çalışmada, $20 \pm 1^{\circ} \mathrm{C}$ ortam sıcaklığı, $\% 50 \pm 5$ bağll nem ve $101 \pm 1 \mathrm{kPa}$ atmosfer basıncı uygun değerler olarak saptanmış ve tüm deneyler bu koşullarda gerçekleștirilmiştir. 
Deney ortamının deniz seviyesinden yüksekliği 8 m'dir. Vakum pompalarının hava debilerinin saptanması sırasında, vakum pompası hava giriş hattı vakum tankından ayrılmış ve bu kısma 3000 L/dak hava ölçüm kapasitesine sahip orifis tipi mekanik bir debi ölçer (AFM 3000 marka, 0-3000 L ölçüm aralıklı, ATV Agri Products, Netherlands) bağlanmıștır. Sağım sisteminin standartlarda belirtilen vakum basınçları dikkate alınarak, pompaların 42, 44, 46, 48 ve $50 \mathrm{kPa}$ vakum basınçlarında ölçümleri yapılmıştır. Pompanın vakum değişimleri, debi ölçer üzerindeki giriş deliğine bir hortum ile bağlanan $0.1 \mathrm{kPa}$ ölçüm hassasiyetli dijital bir vakum ölçerle (DVPM-01 marka, 0-100 kPa vakum ve atmosfer basınç aralıklı, ATV Agri Products, Netherlands) izlenmiștir. Pompaların güç ve enerji ihtiyacının belirlenebilmesi için dijital trifaze elektrik sayacı (Kaan marka 103 tipi) kullanılmıştır. Deneylerde ayrıca motor-pompa dönü sayıları, pompa yağ tüketimi ve maksimum pompa basıncı ölçümleri yapılmıştır. Pompa giriş borusuna bağlanan debi ölçerin hava kanalları tümüyle kapatılarak vakum ölçer ile pompaların maksimum vakum basınçları ölçülmüștür. Pompaların așırı yüklenmeye maruz kalmaması için basıncın kısa sürede ölçümleri yapılmıștır. Pompa devir sayıları için $1 \mathrm{dev} /$ dak hassasiyetli mekanik temaslı dijital göstergeli bir takometre (Shimpo EE1, Digital Tachometer, Japan) kullanılmıştır. Pompaların gürültü seviyesini ölçmek için 0.1 desibel hassasiyetli, 35-130 dB aralıkta ölçüm yapabilen dijital bir desibelmetre (TES 1350 Sound Level Meter) kullanılmıștır. Gürültü seviye ölçümleri pompaların her vakum basıncı için ön, arka ve yan taraflarında birer metre mesafelerde yapılmış ve ortalaması alınmıştır. Vakum pompasının basınç değişimlerindeki hava debisi, güç ihtiyacı ve gürültü değerleri üç tekrarlı olarak ölçülmüştür. Sonuçlar MINITAB (Versiyon 14, Texas Üniversitesi, Austin, ABD) ve MS-Excel yazılım programları tarafindan analiz edilmiştir. Sonuçların analizinde tek yönlü varyans analizi ve LSD testi MSTAT-C (Sürüm 2.1., Michigan State University, USA) yazılım programı kullanılmıştır. Aksi belirtilmedikçe, farklar $\mathrm{P}<0.05$ 'te anlamlı kabul edilmiştir.

\section{Bulgular ve Tartışma}

Araştırmada kullanılan dört farklı tip vakum pompasının 42-50 kPa basınç aralıklarındaki motor ve pompa devir sayıları ile yağ tüketimi değerleri Çizelge 2'de verilmiştir. Denemelerde elektrik motoru ve pompa devirleri ile yağ tüketimlerinin farklı vakum basıncı değișimlerinden etkilenmediği, tüm basınçlarda aynı devir sayılarını ve yă̆ tüketimini verdiği belirlenmiștir. Diğer yandan pompaların kendi aralarındaki motor devir sayılarında ve maksimum pompa basınçlarında istatistiki olarak bir fark olmamış ( $\mathrm{P}>0.05)$, ancak pompa devir saylarında ve yağ tüketimlerinde istatistiki olarak fark bulunmuştur $(\mathrm{P}<0.05)$.

Çizelge 2. Vakum pompalarının motor ve pompa devirleri, maksimum pompa basıncl, yağ tüketimi ölçüm sonuçları

\begin{tabular}{ccccc}
\hline Parametre & \multicolumn{4}{c}{ Vakum pompası tipi } \\
\cline { 2 - 5 } & VP-1 & VP-2 & VP-3 & VP-4 \\
\hline $\begin{array}{c}\text { Elektrik motoru devri, } \\
\text { dev/dak }\end{array}$ & $\begin{array}{c}1450 \\
\text { ö }\end{array}$ & $\begin{array}{c}1440 \\
\text { öD }\end{array}$ & $\begin{array}{c}1452 \\
\text { öD }\end{array}$ & $\begin{array}{c}1430 \\
\text { öD }\end{array}$ \\
\hline $\begin{array}{c}\text { Vakum pompası devri, } \\
\text { dev/dak }\end{array}$ & $1166^{\mathrm{b}}$ & $1088^{\mathrm{c}}$ & $1040^{\mathrm{d}}$ & $\begin{array}{c}1244 \\
\mathrm{a}\end{array}$ \\
\hline $\begin{array}{c}\text { Maksimum pompa } \\
\text { basıncı, kPa }\end{array}$ & $\begin{array}{c}93.9 \\
\text { ô }\end{array}$ & $\begin{array}{c}96.1 \\
\text { ö }\end{array}$ & $\begin{array}{c}96.0 \\
\text { öD }\end{array}$ & $\begin{array}{c}94.3 \\
\text { öD }\end{array}$ \\
\hline $\begin{array}{c}\text { Pompa yağ tüketimi, } \\
\text { mL/h }\end{array}$ & $4^{\mathrm{d}}$ & $8^{\mathrm{c}}$ & $10^{\mathrm{b}}$ & $12^{\mathrm{a}}$ \\
\hline $\begin{array}{c}\text { a-d: Aynı satırda farklı harflerle ifade edilen ortalamalar arasındaki } \\
\text { fark önemlidir (P<0.05); ÖD: Önemli değil. }\end{array}$ & &
\end{tabular}

Pompaların farklı vakum basınçlarındaki (42-50 $\mathrm{kPa}$ ) hava debisi ilişkileri Çizelge 3'te verilmiştir. Çizelgede görüldüğü gibi $42 \mathrm{kPa}$ basınçta en yüksek debi değeri 2167 L/dak ile VP-4 tipi pompada, en düşük debi değeri ise 695 L/dak ile VP-1 tipi pompada ölçülmüştür. Diğer taraftan $50 \mathrm{kPa}$ basınçta en düşük debi 583 L/dak ile VP-1 tipi pompada, en yüksek debi değeri de $1742 \mathrm{~L} /$ dak ile VP-4 tipi pompada ölçülmüştür. Pompalar içinde standartların belirttiği anma kapasitesini $(50 \mathrm{kPa})$ VP-2 ve VP-3 tipi pompalar sağlamıștır. VP-1 pompası \%3, VP-4 pompa ise kapasitesinin \%13 düzeyinde daha az hava debisi vermiștir. Pompa basıncı artışına bağlı olarak hava debisi azalma oranları incelendiğinde, en fazla azalma oranı \%19.6 ile VP-4 tipi pompada bulunmuștur. Bunu sırasıyla \%19.4 ile VP-3, \%17.5 ile VP-2 ve \%16.1 ile VP-1 tipi pompalar izlemiștir. Mein ve ark. (1994) nın buldukları sonuçlar, bu çalışmada elde edilen sonuçları desteklemektedir. Pompaların kendi gruplarındaki basınç aralıklarında yapılan istatiski analize göre ölçülen hava debisi değerleri arasındaki farklar önemli bulunmuştur $(\mathrm{P}<0.05)$. Vakum pompaları birbirinden farklı kapasitelerde olduklarından, bunlar arasında fark olması kaçınılmazdır. Burada asıl vurgulanan, basınç farkları arasında pompa kapasitelerinin istatistiki olarak önemli ölçüde değişip değiş̧mediğidir. Elde edilen sonuçlar bunu kanıtlamıştır. 
Çizelge 3. Pompaların farklı vakum basınçlarına göre hava debisi (L/dak) değerleri

\begin{tabular}{ccccc}
\hline $\begin{array}{c}\text { Vakum } \\
\text { basincl, } \\
\mathrm{kPa}\end{array}$ & VP-1 & VP-2 & VP-3 & VP-4 \\
\cline { 2 - 5 } & $695 \pm 3^{\mathrm{a}}$ & $1458 \pm 36^{\mathrm{a}}$ & $1948 \pm 40^{\mathrm{a}}$ & $2167 \pm 56^{\mathrm{a}}$ \\
42 & $663 \pm 3^{\mathrm{ab}}$ & $1383 \pm 42^{\mathrm{ab}}$ & $1830 \pm 44^{\mathrm{ab}}$ & $2073 \pm 69^{\mathrm{ab}}$ \\
44 & $632 \pm 5^{\mathrm{bc}}$ & $1333 \pm 51^{\mathrm{bc}}$ & $1742 \pm 45^{\mathrm{bc}}$ & $1943 \pm 62^{\mathrm{bc}}$ \\
48 & $602 \pm 8^{\mathrm{c}}$ & $1278 \pm 52^{\mathrm{cd}}$ & $1660 \pm 49^{\mathrm{cd}}$ & $1835 \pm 64^{\mathrm{cd}}$ \\
50 & $583 \pm 4^{\mathrm{c}}$ & $1203 \pm 40^{\mathrm{d}}$ & $1570 \pm 38^{\mathrm{d}}$ & $1742 \pm 64^{\mathrm{d}}$ \\
\hline a-d: Aynı & sütunda farklı harflerle & ifade edilen & ortalamalar \\
arasindaki fark önemlidir (P<0.05). & & &
\end{tabular}

Pompaların farklı basınçlardaki güç gereksinimleri incelendiğinde, $42 \mathrm{kPa}$ basınçtaki en yüksek güç $\mathrm{VP}$ 4 pompasında (4.66 kW), en düşük güç ise VP-1 pompasında $(1.48 \mathrm{~kW})$ bulunmuştur (Çizelge 4). Pompaların $50 \mathrm{kPa}$ basınçlarında ise en yüksek güç ihtiyacı 1.62 ve $4.92 \mathrm{~kW}$ ile sirasiyla yine VP-1 ve VP4 tipi pompalarda ölçülmüştür. Çizelgede görüldüğü üzere pompa basıncının artışı vakum pompası güç ihtiyacı değerlerini de artırmıştır. En yüksek güç artış oranları VP-1 ve VP-4 tipi pompalarda (ortalama \%13) belirlenmiștir. Pompaların kendi gruplarındaki basınç aralıklarında yapılan istatistiki analize göre ölçülen güç değerleri arasındaki farklar önemli bulunmuştur $(\mathrm{P}<0.05)$.

VP-4 tipi pompa hariç diğer tüm vakum pompaları anma motor güçlerinin altında güç tüketmiştir. VP-4 tipi pompa, VP-3 pompası ile aynı teknik özelliklere ve elektrik motoruna sahip olmasına karşın, kayışkasnakla devir artışı sağlanarak hava kapasitesinin artırılma yoluna gidilmiştir. Ancak, güç gereksinimi sonuçları incelendiğinde, bu pompa devrinin artırılmasının, $42 \mathrm{kPa}$ basınçta \%16, $50 \mathrm{kPa}$ basınçta ise \%23 daha fazla oranda motorun aşırı yüklendiği saptanmıştır. Buradan, motorun VP-4 pompasını çalıştırmak için şebekeden fazla akım çektiği anlaşılmaktadır. Pompanın mevcut motor ile kullanılması motor ömrünü kısalttığı gibi tehlike riski de taşımaktadır. Kullanılan mevcut VP-4 tipi pompa için ya anma gücü $5.5 \mathrm{~kW}$ olan motor seçilmesi ya da pompa yapısal kapasitesinin büyütülerek buna uygun motor seçiminin yapılması önerilir.

Vakum pompalarının birim güç ihtiyacından hesaplanan pompa debileri Çizelge 5 'te verilmiştir. Çizelgede görüldüğ̈ü gibi, $42 \mathrm{kPa}$ 'da birim güç başına en yüksek pompa debisi $556.6 \mathrm{~L} /$ dak kW ile VP-3 tipi pompada, en düşük ise $441.4 \mathrm{~L} / \mathrm{dak} \mathrm{kW}$ ile VP-1 tipi pompada belirlenmiștir. Pompaların $50 \mathrm{kPa}$ basınçlarında ise yine aynı tip pompalarda (sırasıyla 401.8 ve 327.8 L/dak kW) elde edilmiştir. Pompa basıncı arttıkça birim güç başına debi de düşmektedir. Çizelge incelendiğinde, en yüksek düşüş oranı yaklaşılk \%28 ile VP-3 ve VP-4 tipi pompalarda bulunmuştur. En düşük düşüş oranı ise \%25.7 ile VP-1 tipi pompada belirlenmiștir.

Çizelge 4. Pompaların farklı vakum basınçlarına göre güç gereksinimi $(\mathrm{kW})$ değerleri

\begin{tabular}{|c|c|c|c|c|}
\hline \multirow{2}{*}{$\begin{array}{c}\text { Vakum } \\
\text { basıncı, } \\
\mathrm{kPa}\end{array}$} & \multicolumn{4}{|c|}{ Vakum pompası tipi } \\
\hline & VP-1 & VP-2 & VP-3 & VP-4 \\
\hline 42 & $1.48 \pm 0.01^{\mathrm{c}}$ & $2.73 \pm 0.02^{\mathrm{e}}$ & $3.55 \pm 0.04^{\mathrm{d}}$ & $4.66 \pm 0.02^{\mathrm{d}}$ \\
\hline 44 & $1.51 \pm 0.01^{b c}$ & $2.77 \pm 0.02^{\mathrm{d}}$ & $3.61 \pm 0.01^{c}$ & $4.72 \pm 0.01^{\mathrm{cd}}$ \\
\hline 46 & $1.54 \pm 0.01^{b}$ & $2.82 \pm 0.01^{\mathrm{c}}$ & $3.74 \pm 0.01^{\mathrm{b}}$ & $4.76 \pm 0.03^{c}$ \\
\hline 48 & $1.59 \pm 0.02^{\mathrm{a}}$ & $2.88 \pm 0.02^{b}$ & $3.83 \pm 0.03^{a}$ & $4.84 \pm 0.03^{b}$ \\
\hline 50 & $1.62 \pm 0.01^{\mathrm{a}}$ & $2.94 \pm 0.03^{\mathrm{a}}$ & $3.87 \pm 0.02^{\mathrm{a}}$ & $4.92 \pm 0.07^{\mathrm{a}}$ \\
\hline
\end{tabular}

Pompaların vakum artışına bağlı olarak birim güç başına debi düşüşleri arasında istatistiki olarak önemli fark vardır $(\mathrm{P}<0.05)$. Diğer yandan, her basınç için pompaların kendi aralarında da önemli farklar bulunmuştur $(\mathrm{P}<0.05)$. Burada, VP-3 vakum pompası tüm basınçlarda en verimli pompa olarak öne çılkmıştır.

Çizelge 5. Pompaların farklı vakum basınçlarına göre birim güç başına hava debisi (L/dak $\mathrm{kW}$ ) değerleri

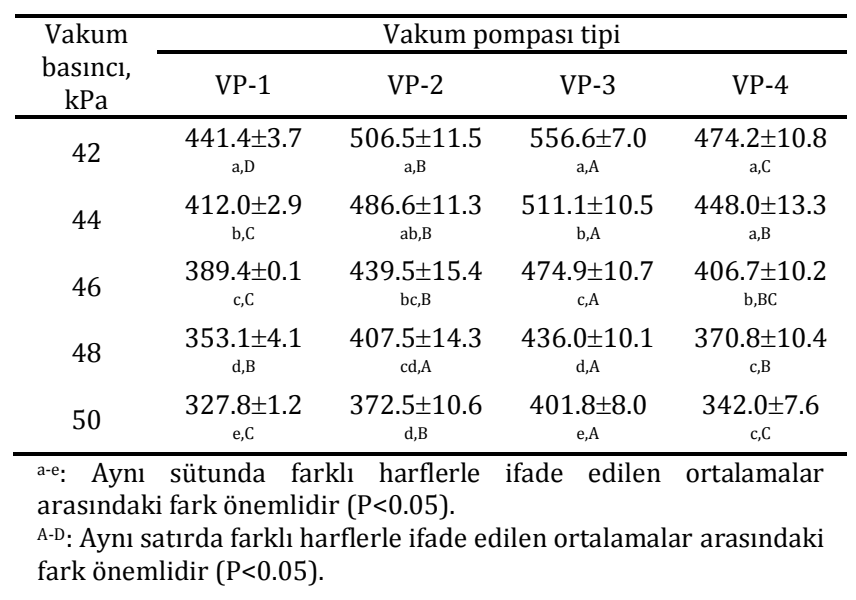

Vakum pompalarının farklı pompa basınçlarında sistemden çektiği birim hava miktarına göre özgül enerji tüketimleri $(\mathrm{Wh} / \mathrm{L})$ incelendiğinde, 42 ve 50 $\mathrm{kPa}$ pompa basınçlarında en düşük özgül enerji tüketimi 0.030 ve $0.042 \mathrm{Wh} / \mathrm{L}$ ile VP-3 tipi pompada, aynı basınçlarda en yüksek özgül enerji tüketimi ise 0.038 ve $0.051 \mathrm{Wh} / \mathrm{L}$ ile VP-1 tipi pompada gerçekleşmiştir (Çizelge 6). Tüm vakum pompalarının 42-50 basınç aralıklarında enerji 
tüketimleri arasında istatistiki olarak farklılıklar bulunmuştur $(\mathrm{P}<0.05)$. Pompa basıncı arttıkça enerji tüketiminin arttığı belirlenmiştir. Yapılan istatistikler sonucunda pompa tiplerinin 46 ve 48 $\mathrm{kPa}$ basınçlarındaki enerji tüketimleri arasında istatistiki olarak farklar önemli çıkmıştır $(\mathrm{P}<0.05)$. Pompaların 42, 44 ve $50 \mathrm{kPa}$ basınçlarındaki özgül enerji tüketimleri arasında ise fark önemli çlkmamıştır ( $\mathrm{P}>0.05)$.

Çizelge 6. Pompaların farklı vakum basınçlarında birim hava miktarına göre özgül enerji tüketim (Wh/L) değerleri

\begin{tabular}{|c|c|c|c|c|}
\hline \multirow{2}{*}{$\begin{array}{c}\text { Vakum } \\
\text { basincı, } \\
\mathrm{kPa}\end{array}$} & \multicolumn{4}{|c|}{ Vakum pompası tipi } \\
\hline & VP-1 & VP-2 & VP-3 & VP-4 \\
\hline 42 & $\begin{array}{c}0.038 \pm \\
0.000^{\mathrm{b}, \mathrm{DD}}\end{array}$ & $\begin{array}{c}0.033 \pm \\
0.001^{\mathrm{b}, \mathrm{O} \mathrm{D}}\end{array}$ & $\begin{array}{c}0.030 \pm \\
0.000^{\mathrm{b}, \mathrm{o} \mathrm{D}}\end{array}$ & $\begin{array}{c}0.035 \pm \\
0.001^{\mathrm{b}, \mathrm{D}} \mathrm{D}\end{array}$ \\
\hline 44 & $\begin{array}{c}0.040 \pm \\
0.000^{\mathrm{b}, \mathrm{o} \mathrm{D}}\end{array}$ & $\begin{array}{c}0.036 \pm \\
0.001^{\mathrm{b}, \mathrm{O} \mathrm{D}}\end{array}$ & $\begin{array}{c}0.033 \pm \\
0.001^{\mathrm{b}, \mathrm{oD}}\end{array}$ & $\begin{array}{c}0.037 \pm \\
0.001^{\mathrm{b}, \mathrm{O} \mathrm{D}}\end{array}$ \\
\hline 46 & $\begin{array}{c}0.043 \pm \\
0.000^{\mathrm{a}, \mathrm{A}}\end{array}$ & $\begin{array}{c}0.038 \pm \\
0.001 \mathrm{~b}, \mathrm{~B}\end{array}$ & $\begin{array}{c}0.035 \pm \\
0.001 \mathrm{~b}, \mathrm{~B}\end{array}$ & $\begin{array}{c}0.041 \pm \\
0.001^{\mathrm{b}, \mathrm{A}}\end{array}$ \\
\hline 48 & $\begin{array}{r}0.047 \pm \\
0.001^{\mathrm{a}, \mathrm{A}}\end{array}$ & $\begin{array}{c}0.041 \pm \\
0.001^{\mathrm{b}, \mathrm{B}}\end{array}$ & $\begin{array}{c}0.038 \pm \\
0.001^{\mathrm{b}, \mathrm{B}}\end{array}$ & $\begin{array}{c}0.045^{ \pm} \\
0.001^{\mathrm{a}, \mathrm{A}}\end{array}$ \\
\hline 50 & $\begin{array}{c}0.051 \pm \\
0.000^{\mathrm{a}, \mathrm{o} \mathrm{D}}\end{array}$ & $\begin{array}{c}0.045 \pm \\
0.001^{\mathrm{a}, \mathrm{O} D \mathrm{D}}\end{array}$ & $\begin{array}{c}0.042 \pm \\
0.001^{\mathrm{a}, \mathrm{O} \mathrm{D}}\end{array}$ & $\begin{array}{c}0.049 \pm \\
0.001^{\mathrm{a}, \mathrm{D} D}\end{array}$ \\
\hline
\end{tabular}

a-b: Aynı sütunda farklı harflerle ifade edilen ortalamalar arasındaki fark önemlidir $(\mathrm{P}<0.05)$.

A-B: Aynı satırda farklı harflerle ifade edilen ortalamalar arasındaki fark önemlidir $(\mathrm{P}<0.05)$

öD: önemli değil.

Vakum pompalarının yine farklı basınç değerlerindeki gürültü seviyesi sonuçları incelendiğinde, $42 \mathrm{kPa}$ pompa basıncında en düşük gürültü seviyesi VP-2 tipi pompada (88.7 dB-A), en yüksek gürültü seviyesi ise VP-1 tipi vakum pompasında (90.9 dB-A) ölçülmüştür. $50 \mathrm{kPa}$ basıncında ise en düşük ve en yüksek gürültü seviyeleri yine sirasiyla VP-2 ve VP-1 pompalarda sırasıyla 89.6 ve 92.2 dB-A değerlerinde ölçülmüștür (Çizelge 7). Tüm vakum pompalarının 42-50 kPa basınç aralıklarındaki gürültü seviyeleri arasında istatistiki olarak farklılıklar vardır $(\mathrm{P}<0.05)$. Diğer yandan her basınç için pompaların kendi aralarındaki gürültü düzeyleri incelendiğinde, VP-2 pompanın gürültü seviyesi diğer pompalardan düşüktür. VP-1, VP-3 ve VP-4 pompalarının gürültü düzeyleri arasında önemli bir fark bulunmamıştır.

Literatürde sağım odasında sağımcı ve hayvanların olumsuz etkilenmemesi için ortalama gürültü düzeyi 75 dB-A düzeyinde olması önerilir. Bu nedenle, giriş bölümünde belirtildiği gibi; bu durumda, inekler sağım odasına girmek istemez, inekler memelerinin tamamen boşaltılmasına izin vermez, sağım sırasında ve sonrasında kendini iyi hissetmez ve strese girer (Nosal ve Bilgery, 2004).

Çizelge 7. Pompalarının farklı vakum basınçlarına göre gürültü $(\mathrm{dB}-\mathrm{A})$ düzeyleri

\begin{tabular}{ccccc}
\hline \multirow{2}{*}{$\begin{array}{c}\text { Vakum } \\
\text { basincl, } \\
k P a\end{array}$} & VP-1 & VP-2 & VP-3 & VP-4 \\
\cline { 2 - 5 } & & & & \\
\hline 42 & $90.9 \pm 0.2^{\mathrm{c}, \mathrm{A}}$ & $88.7 \pm 0.3^{\mathrm{c}, \mathrm{B}}$ & $90.8 \pm 0.3^{\mathrm{c}, \mathrm{A}}$ & $90.6 \pm 0.2^{\mathrm{c}, \mathrm{A}}$ \\
44 & $91.4 \pm 0.1^{\mathrm{b}, \mathrm{A}}$ & $88.9 \pm 0.1^{\mathrm{bc}, \mathrm{B}}$ & $91.3 \pm 0.2^{\mathrm{b}, \mathrm{A}}$ & $91.2 \pm 0.2^{\mathrm{b}, \mathrm{A}}$ \\
46 & $91.7 \pm 0.3^{\mathrm{ab}, \mathrm{A}}$ & $89.1 \pm 0.2^{\mathrm{b}, \mathrm{B}}$ & $91.6 \pm 0.2^{\mathrm{ab}, \mathrm{A}}$ & $91.5 \pm 0.2^{\mathrm{ab}, \mathrm{A}}$ \\
48 & $91.9 \pm 0.1^{\mathrm{ab}, \mathrm{A}}$ & $89.4 \pm 0.1^{\mathrm{ab}, \mathrm{B}}$ & $91.8 \pm 0.4^{\mathrm{ab}, \mathrm{A}}$ & $91.8 \pm 0.4^{\mathrm{ab}, \mathrm{A}}$ \\
50 & $92.2 \pm 0.3^{\mathrm{a}, \mathrm{A}}$ & $89.6 \pm 0.3^{\mathrm{a}, \mathrm{B}}$ & $92.0 \pm 0.4^{\mathrm{a}, \mathrm{A}}$ & $92.1 \pm 0.2^{\mathrm{a}, \mathrm{A}}$ \\
\hline
\end{tabular}

a-c: Aynı sütunda farklı harflerle ifade edilen ortalamalar arasındaki fark önemlidir $(\mathrm{P}<0.05)$.

A-B: Aynı satırda farklı harflerle ifade edilen ortalamalar arasındaki fark önemlidir $(\mathrm{P}<0.05)$.

Vakum pompalarının $42-50 \mathrm{kPa}$ aralığındaki basınçlarda hava kapasitesi, güç ve özgül enerji tüketimi, birim güç başına pompa hava debisive gürültü seviyesini belirlemek için regresyon ilişkileri incelenmiş ve aşağıdaki temel dekleme göre eşitlikleri geliştirilmiştir (Çizelge 8).

$$
Y=A+B P_{p}
$$

Çizelge 8'de görüldüğü gibi, vakum basıncı değişimlerine göre elde edilen tüm eşitliklerde determinasyon katsayıları yüksek doğruluklarda bulunmuştur. Hava kapasitesi-basınç, güç-basınç, özgül enerji-basınç, birim güç başına hava debisibasınç ve gürültü-basınç ilişkileri için elde edilen eşitlikler güvenilir şekilde kullanılabilir. Tan ve ark. (1992) tarafından elde edilen regresyon denklemleri bu çalışmada bulunan sonuçlarla benzerlik göstermiştir. $\mathrm{Bu}$ araştırmada vakum pompalarının farklı basınçlarda ürettikleri hava kapasitelerinden giderek sağım yapabilecekleri maksimum sağım ünitesi sayıları da belirlenmiştir (Çizelge 9). Hesaplamalarda kovalı süt sağım makinaları ve süt borulu sağım tesisleri için standartlarda ve referanslarda belirtilen rakımlara göre aşağıdaki ana parametreler dikkate alınmıştır (Reinemann ve ark. (2001); Billon, 2004; Bilgen ve Öz, 2006; TS ISO 5707, 2014; TS ISO 6690, 2014).

- Yedek kapasite, (Kovalı sağım makiası için 1-10 arası: $80+25 . n$ ve 10 'dan fazla: $330+10 .(n-10)$; Süt borulu tesisler için 1-10 arası: $200+30 . n$ ve 10 'dan fazla $500+10 .(n-10)$ dur.)

- Sağım ünitesi hava gereksinimi, (pnömatik 50.n L/dak; elektronik 35. $n$ L/dak)

- Regülasyon kaybı, (35 L/dak) 
- 1. ara toplam,

- Rakıma bağlı düzeltme faktörü $(0-300 \mathrm{~m}$ arasında),

- 2. ara toplam,

- Hava hattı kaçağı ((2. ara toplam/0.95)*0.05)
- Vakum pompasının her rakım aralığındaki toplam hava kapasitesi (2. ara toplam + hava hattı kaçağı) (L/dak).

Burada, $n$ sağım ünitesi sayıdır.

Çizelge 8. Pompalarının farklı vakum basınçlarına göre bazı parametrelerinin regresyon ve determinasyon katsayıları

\begin{tabular}{|c|c|c|c|}
\hline \multirow{2}{*}{$\begin{array}{c}\text { Parametre } \\
(\mathrm{Y})\end{array}$} & \multicolumn{2}{|c|}{ Regresyon katsayıları } & \multirow{2}{*}{ Determinasyon katsayısı $\left(\mathrm{R}^{2}\right)$} \\
\hline & (A) & (B) & \\
\hline \multicolumn{4}{|l|}{ Hava kapasitesi (L/dak) } \\
\hline$Q_{V P-1}$ & 1225.5 & -13.42 & 0.992 \\
\hline$Q_{V P-2}$ & 2729.7 & -31.17 & 0.997 \\
\hline$Q_{V P-3}$ & 3881.3 & -46.33 & 0.995 \\
\hline$Q_{V P-4}$ & 4441.3 & -53.0 & 0.994 \\
\hline \multicolumn{4}{|l|}{ Güç gereksinimi (kW) } \\
\hline $\mathrm{N}_{\mathrm{VP}-1}$ & 0.45 & 0.025 & 0.958 \\
\hline $\mathrm{N}_{\mathrm{VP}-2}$ & 1.11 & 0.040 & 0.991 \\
\hline $\mathrm{N}_{\mathrm{VP}-3}$ & 1.30 & 0.052 & 0.990 \\
\hline $\mathrm{N}_{\mathrm{VP}-4}$ & 1.39 & 0.077 & 0.995 \\
\hline \multicolumn{4}{|c|}{ Özgül enerji tüketimi (Wh/L) } \\
\hline ÖET & -0.0319 & 0.0016 & 0.986 \\
\hline ÖET $T_{\mathrm{VP}-2}$ & -0.0285 & 0.0015 & 0.992 \\
\hline ÖET ${ }_{V P-3}$ & -0.0306 & 0.0014 & 0.997 \\
\hline ÖET & -0.0389 & 0.0017 & 0.990 \\
\hline \multicolumn{4}{|c|}{ Birim güç bașına hava debisi (L/dak kW) } \\
\hline$\eta_{V P-1}$ & 1042.9 & -14.31 & 0.996 \\
\hline$\eta_{\mathrm{VP}-2}$ & 1195.8 & -16.45 & 0.999 \\
\hline$\eta_{V P-3}$ & 1360.9 & -19.24 & 0.998 \\
\hline$\eta_{\mathrm{VP}-4}$ & 1193.9 & -17.08 & 0.995 \\
\hline \multicolumn{4}{|l|}{ Gürültü seviyesi (dB-A) } \\
\hline $\mathrm{S}_{\mathrm{VP}-1}$ & 84.49 & 0.155 & 0.968 \\
\hline $\mathrm{S}_{\mathrm{VP}-2}$ & 83.98 & 0.112 & 0.991 \\
\hline $\mathrm{S}_{\mathrm{VP}-3}$ & 84.53 & 0.152 & 0.969 \\
\hline $\mathrm{S}_{\mathrm{VP}-4}$ & 83.24 & 0.178 & 0.964 \\
\hline
\end{tabular}

Vakum pompalarının deniz seviyesinde farklı işletme vakum basınçlarına göre ölçülen hava kapasiteleri (Çizelge 3'te verilen) ile hesaplanan minimum hava kapasiteleri karşılaştırıldığında, sağım makinasının sağım yapabileceği maksimum ünite sayıları Çizelge 9'da verilmiştir. VP-1 vakum pompası gügüme veya doğrudan kovaya sağım yapan yarı sabit süt sağım makinalarında kullanıldığından, $42 \mathrm{kPa}$ basınçta maksimum 8 ünite, $50 \mathrm{kPa}$ da ise maksimum 4 üniteye hizmet verebileceği bulunmuştur. Diğer taraftan VP-4 pompası aynı basınçlarda sırasıyla 34 ve 21 sağım ünitesine hizmet edebilecektir. VP-3 tipi pompa ile VP-4 pompa arasinda sadece devir farklılığı olduğundan, VP-3 pompanın sağım yapabileceği ünite sayısının daha başarılı olduğu anlaşılmaktadır. Süt sığırcılığı işletmelerinde zorunlu olmadıkça yüksek süt boru hatlı tesislerin kurulması önerilmemektedir. Bu tip tesislerde sağılan sütün ayrıca yükseğe taşınabilmesi için ilave vakuma ihtiyaç olduğundan, tesisin yaklaşık $48-50 \mathrm{kPa}$ işletme basınçlarda çalıştırılması gerekmektedir.
Yüksek basınçlar, hayvanın meme başı ucunda deformasyona sebep olabilmekte ve hayvanı strese sokabilmektedir. $\mathrm{Bu}$ yüzden sağım platformu zemininden aşağıya kurulan alçak süt hatlı sağım tesislerinde yaklaşı $42-44 \mathrm{kPa}$ işletme vakum basınçları tercih edilmelidir.

Çizelge 9. Pompaların deniz seviyesinde farklı vakum basınçlarında sağım yapabileceği maksimum sağım ünitesi sayısı

\begin{tabular}{ccccc}
\hline $\begin{array}{r}\text { Vakum } \\
\text { basıncı, } \\
\text { kPa }\end{array}$ & VP-1 & VP-2 & VP-3 & VP-4 \\
\cline { 2 - 5 } & 8 & 20 & 30 & 34 \\
44 & 7 & 19 & 27 & 31 \\
46 & 6 & 17 & 24 & 27 \\
48 & 5 & 15 & 21 & 24 \\
50 & 4 & 13 & 19 & 21 \\
\hline
\end{tabular}

\section{Sonuç}

Çalışmada vakum pompalarının farklı vakum basınçlarındaki sonuçları aşağıda özetlenmiştir: 
- Vakum pompalarının 42-50 $\mathrm{kPa}$ basınç aralıklarındaki motor ve pompa devirleri ile yağ tüketimlerinde herhangi bir değișme olmamıștır. Diğer taraftan pompa tipleri arasında pompa devir sayısı ve yağ tüketimleri arasında istatiki olarak fark görülürken, motor devir sayısı ve maksimum pompa basınçlarında bir fark olmamış $(\mathrm{P}>0.05)$.

- Pompalar içinde firmanın belirttiği kapasiteye 50 $\mathrm{kPa}$ basınçta VP-2 ve VP-3 tipi pompalar ulaşmıştır.

- VP-4 tipi pompanın devrinin artırılması, $42 \mathrm{kPa}$ basınçta \%16, $50 \mathrm{kPa}$ basınçta ise $\% 23$ daha fazla oranda anma motor gücünün üzerinde güç tüketmiştir. Bu pompada kullanılan norm motor gücünün ya $5.5 \mathrm{~kW}$ 'a çıkarılması ya da pompa yapısal kapasitesinin büyütülerek buna uygun motor seçilmesi önerilir.

- Tüm vakum basınçlarında en yüksek birim güç başına hava debilerini sırasıyla VP-3 ve VP-2 tipi pompalar sağlarken, bunları VP-4 ve VP-1 pompaları izlemiştir.

- Vakum pompalarının sistemden çektiği birim hava miktarına göre özgül enerji tüketimleri (Wh/L) hesaplandığında, 42 ve $50 \mathrm{kPa}$ pompa basınçlarında en düşük özgül enerji tüketimi sirasiyla 0.030 ve $0.042 \mathrm{Wh} / \mathrm{L}$ ile VP-3 tipi pompada belirlenmiş, bunu sırasıyla VP-2, VP-4 ve VP-1 tipi pompalar izlemiştir.

- Tüm vakum basınçlarında, en düşük gürültü seviyesi VP-2 tipi pompada ölçülmüștür. Diğer üç pompanın gürültü seviyeleri birbirine yakın bulunmuştur.

- Vakum pompalarının deniz seviyesinde $50 \mathrm{kPa}$ pompa basıncında sağım yapabileceği maksimum ünite sayısı VP-1 pompası için 4 adet iken, VP-2, VP-3 ve VP-4 pompaları için sırasıyla 13, 19 ve 21 adettir.

Süt sağım makinasının önemli elemanlarından olan ve ülkemizde yaygın olarak kullanılan döner kanatlı tip vakum pompalarının farklı işletme basınçları için bu çalışmada elde edilen bulgular, vakum pompaları üzerinde çalışan araştırmacılara, üretici firmalara ve hayvancılıkla uğraşanlara yardımcı olabileceği düşünülmektedir.

\section{Teşekkür}

Çalışmadaki vakum pompalarında araştırma imkânı sağlayan Sezer Tarım ve Sağım Teknolojileri San. Tic. Ltd. Şti. yönetici ve çalışanlarına teşekkür ediyoruz.

\section{Kaynaklar}

Anonim, 2012. On vacuum pumps and milking machines. (http://www.unitedvacuum.com/blog/), (Erișim: 15.05.2018).

Bilgen, H., Öz, H., 2006. Süt sağım makina ve tesislerinin standartlara uygun kontrolleri. Ege Üniversitesi, Ziraat Fakültesi, Yayınları No: 10, 77 s., İzmir.

Billon, P., 2004. The designing of small and medium sized milking machines for dairy sheep. In: Proc, $10^{\text {th }}$ Great Lakes Dairy Sheep Symposium, Eau Claire, Wisconsin, Nov. 4-6, 2004.

Bray, D.R., 1996. Requirements of a milking system. Institute of Food and Agricultural Sciences, University of Florida. (http://edis.ifas.ufl.edu/), (Erișim: 24.04.2018).

Chilvers, R.A.H., Love, D.J., 1986. Measuring vacuum pump performance. Proceedings of the South African Sugar Technologists' Association, 138-142.

Mein, G.A., Bray, D.R., Collar, L.S., Johnson, A., Spencer, S.B., 1994. Sizing vacuum pumps for milking. National Mastitis Council, Proceedings of the $33^{\text {th }}$ Annual Meeting: National Mastitis Council, 124-133.

Mein, G.A., Bray, D.R., Brazil, L.H., Collar, L.S., Johnson, A.P., Spencer, S.B., 1995. Effective reserve and vacuum pump capacity for milking. Proceedings of the $34^{\text {th }}$ Annual Meeting, TX.

Nosal, D., Bilgery, E., 2004. Airborne noise, structure-borne sound and vacuum stability of milking systems. Czech Journal of Animal Science, 49(5): 226-230.

Reinemann, D.J., Mein, G.A., Ruegg, P.L., 2001. Evaluating milking machine performance. In VII International Congress on Bovine Medicine, Oviedo, Asturias, Spain, June 29-July 1, 2001.

Tan, J., Janni, K.A., Stelson, K.A., 1992. Mathematical modeling of milking machine vacuum systems. Transactions of the American Society of Agricultural Engineers, 35(1): 327-332.

TS ISO 5707, 2014. Süt Sağım Makina Tesisleri - Yapım ve Performans. Haziran 2014, TSE, 47 s. Ankara.

TS ISO 6690, 2014. Süt Sağım Makina Tesisleri - Mekanik Deneyler. Haziran 2014, TSE, 34 s. Ankara.

Ünal, H., 2013. Süt Sığırcılı̆̆ında Mekanizasyon. Sütaş Süt Hayvancllığı Eğitim Merkezi. ISBN: 978-97593554-4-9, Bursa, Sayl: 9, 73 s. 